\title{
TERMINOGRAFIA JURÍDICA PARA O MERCOSUL E RECURSOS INFORMATIZADOS
}

\author{
Anna Maria Becker Maciel
}

\begin{abstract}
RESUMO: This paper focuses on the need to advance legal terminology and terminography theory and practice in the South Market. Considering the close relationship between law and language, a brief overview of the linguistic panorama of multinational communities where similar studies have been developed is sketched. The fallacy that there are no translation problems between Portuguese and Spanish is discussed as well as the misleading idea of the equivalence of the national legal systems of the member countries. Theoretical and methodological assumptions viewing an approach specifically designed are examined. The value of computerized resources the implementation of terminography is highlighted. Some ideal features for the South Market terminographical production are outlined.
\end{abstract}

PALAVRAS-CHAVE: terminologia jurídica, dicionários jurídicos, bancos de dados terminológicos, terminologia computacional, aplicações para o MERCOSUL.

\section{Introdução}

Considerando a terminografia a investigação das propriedades lingüísticas, conceituais e pragmáticas das unidades terminológicas a fim de produzir obras de referência (BESSÉ et al. 1998), proponho uma reflexão sobre o desenvolvimento da terminografia jurídica no Mercosul. As duas atividades terminográficas básicas, a pesquisa e a prática, têm como meta fazer avançar os estudos da área e, ao mesmo tempo, contribuir para a implementação de recursos que possibilitem uma melhor comunicação na linguagem de especialidade. Em outras palavras, as duas atividades, cada uma de acordo com sua natureza, orientam-se para a elaboração de obras de referência terminológica, tais como dicionários, glossários, léxicos, vocabulários e bancos de dados.

Introduzindo o tema, enfatizo que a necessidade de promover o entendimento entre comunidades uni e multinacionais tem sido o fator responsável pelo avanço dos estudos de terminologia e terminografia jurídicas em áreas em que mais de uma língua é falada e/ou diferentes sistemas jurídicos são adotados. Considero, então, o inter-relacionamento do Direito, disciplina humana e social, e a língua, instrumento de configuração e comunicação de conceitos. A seguir, comento a noção equivocada de que o português e o espanhol não apresentam problemas de tradução e interpretação e de que os sistemas jurídicos dos países do Cone Sul muito se assemelham. Depois disso, examino a fundamentação teórica e as bases metodológicas adequadas ao desenvolvimento da terminografia no contexto do Mercosul. Finalmente, discuto as características ideais de produtos terminográficos derivados dos princípios expostos. Para concluir, afirmo que a terminografia jurídica no Mercosul é empreendimento singular, de grande porte e alcance, que não pode ser confiado unicamente a iniciativas isoladas.

\section{Contato de línguas e sistemas jurídicos diferentes}

O Mercosul se constitui em uma comunidade supranacional, onde línguas e sistemas legais diferentes convivem. Longe de pretender imitar, mas apenas com o fim de usufruir da experiência de comunidades com características semelhantes, menciono o que tem sido feito em outros países, sem esquecer

Anna Maria Becker Maciel é professora do Instituto de Letras da UFRGS

Organon, Porto Alegre, $\mathrm{n}^{\circ}$ 26, 1998 
que cada contexto é único e necessita de um modelo específico. Assim, evoco a situação de países bilíngües e de comunidades multilíngües de nações cuja experiência atesta a incidência de problemas de compreensão, que muitas vezes prejudicam acordos mútuos e projetos conjuntos, quando vários idiomas e várias maneiras de encarar a lei se confrontam no universo do relacionamento jurídico (PALMISCIANO; CHRISTOFFERSEN, 1993; BAUER- BERNET 1982).

A Bélgica, a Holanda, a Áustria e a Itália são exemplos de comunidades que, pressionadas pelas contingências impostas pelo multilingüismo, incentivam estudiosos da língua e juristas a unir esforços em uma contínua investigação da linguagem usada no Direito, quer dentro das próprias fronteiras, quer no âmbito das relações internacionais. O Canadá, onde dois sistemas jurídicos, anglo-saxônico, common law e latino, civil law, e duas línguas oficiais entram em contato, estimula, da mesma maneira, o desenvolvimento de centros de pesquisa principalmente nas províncias de Ottawa, Quebec e Nova Brunswick. A União Européia, UE, que abrange 15 países, entre os quais alguns multilíngües e assiste a convivência de sistemas jurídicos díspares, enfrentaria a confusão de uma colossal Babel, se não dispusesse dos recursos que os avanços da terminologia moderna e da terminografia atualizada oferecem a seus tradutores e intérpretes.

\section{Direito e língua}

Tal situação se explica porque o Direito é um fenômeno sócio-cultural que depende estreitamente do uso da língua. Seu processo de conceitualização não é uma atividade individual separada da comunicação, posto que é fruto de uma construção efetuada em pleno uso da língua em um contexto real. De fato, é através da língua que os conceitos jurídicos ganham forma e, uma vez verbalizados, são transmitidos, configurando uma terminologia com características próprias. Essa terminologia, no processo da comunicação, é vetor de disposições e de normas legais que efetivam a existência do Direito em um domínio ligado a uma língua determinada (SANDRINI, 1995, p. 11). Por esse motivo, os estudos de terminologia jurídica se desenvolvem principalmente nas comunidades, em que a confluência de línguas diferentes coloca entraves ao fluxo ideal da comunicação no mundo das leis.

De tal maneira a realização do Direito está ligada à realização da linguagem, que ousaria dizer que, como um conceito jurídico, o Mercosul nasceu por meio da língua, pois foi um ato de fala na concepção de Austin (1978) que o criou. Realmente, a enunciação de um texto, o Tratado de Assunção (26/01/1991), deu existência a uma pessoa jurídica de Direito Internacional, o Mercado Comum do Cone Sul, reunindo os quatro países da Bacia do Prata. Tal pessoa não é regida pelas legislações nacionais de cada um dos seus membros, mas por normas, elaboradas pelo conselho de seus representantes e reunidas no Código do Mercosul (DROMI, 1996, v. 1, p. 15-39).

O Código do Mercosul, ao disciplinar uma realidade situada acima das nações envolvidas, dispõe sobre conceitos específicos cujo conhecimento só se torna acessível através de termos adequados. Esses termos configuram uma terminologia própria relativa a uma conjuntura política geo-sócio-econômica determinada que se atualiza em um discurso jurídico, mediado pelas línguas espanhola da América do Sul e portuguesa do Brasil.

\section{Falsa imagem de identidade entre línguas e sistemas jurídicos}

Tanto o espanhol, quanto o português são considerados línguas oficiais do Mercosul. A versão original dos documentos gerados cada vez que os países membros se reúnem deve ser redigida no idioma do país sede da reunião e, então, traduzidos para a outra língua. Aparentemente, trata-se de um processo de fácil execução, a passagem direta de uma língua para a outra, sendo a tradução usualmente preparada "ad hoc" e logo publicada pela mídia.

Com efeito, se comparado com a situação da UE, que conta com nove idiomas oficiais, alemão, dinamarquês, espanhol, francês, grego, inglês, irlandês, italiano, e português, o panorama lingüístico do Mercosul afigura-se bastante simples: quatro países, duas línguas semelhantes. Todas as disposições legais oriundas da nova conjuntura política são interpretadas e manifestadas em espanhol e traduzidas para o português ou vice-versa. Acredita-se que a tradução não apresenta problemas, por causa da origem latina comum, do desenvolvimento histórico paralelo e da proximidade geográfica da língua fonte e da língua alvo. Não obstante, apesar das semelhanças, a situação real é bem diferente dessa utopia linguiística.

Embora nascidas da mesma matriz latina, tanto uma como outra língua apresentam características próprias no que diz respeito ao sistema lexical, à estrutura sintática e aos condicionamentos pragmáticos. Tais 
traços peculiares acarretam a ocorrência de falsos cognatos e de construções frasais pretensamente paralelas que podem ocasionar sérios transtornos de comunicação refletidos no relacionamento político.

Basta lembrar a unidade lexical, ganância, de ocorrência comum nas duas línguas. No espanhol, ganancia, simplesmente significa lucro, enquanto no português, tem o sentido de ambição de lucro, ganho indevido e usura, assim, em um contexto a conotação é positiva e no outro, negativa. Além disso, sabe-se que dentro de um país, em um mesmo sistema jurídico, também ocorre a polissemia, isto é, um termo cobre dois ou mais conceitos distintos. Tal ocorrência entre países de idiomas e culturas diferentes agrava o problema, pois a equivalência completa entre dois termos legais é dificilmente alcançada (SARCEVIC, 1991, p. 616).

Também é fictícia a homogeniedade da situação lingüística dos falantes de espanhol, pois a língua espanhola do Mercosul é multifacetada pelas variantes nacionais da Argentina, Paraguai e Uruguai. Ademais, nenhuma dessas variantes do espanhol americano é idêntica ao espanhol ibérico. E ainda, à essa confluência de línguas, é mister acrescentar o guarani, língua oficial com mesmos direitos do espanhol no Paraguai.

Apesar de tudo, nesse cadinho de falares, é preciso garantir a univocidade da comunicação, de modo que, embora usando significantes distintos, todos se refiram ao mesmo significado no contexto jurídico. Nesse sentido, a individualidade de cada um dos idiomas e cada uma das variantes lingüísticas deve ser conservada, posto que univocidade não significa uniformidade. Além do mais, a preservação e o fortalecimento da comunidade do Cone Sul exigem que cada uma das nações componentes preserve sua própria identidade e o respeito à língua nacional é fator de maior importância para essa preservação.

Por outro lado, os sistemas jurídicos do Mercosul, embora compartilhando a mesma tradição da família romano-germânica do Direito, olham a realidade sob prismas diversos. Essa diversidade de enfoque aparece de maneira mais nítida em algumas áreas jurídicas, principalmente no que tange ao Direito Comercial. A raiz dessa diferença encontra-se profundamente arraigada na base conceitual dos modelos jurídicos adotados nos respectivos países. Enquanto, na quase totalidade da América espanhola, o modelo jurídico francês foi a grande influência do legislador, no Brasil, ao lado das Ordenações Portuguesas, foi o modelo alemão que inspirou a codificação das leis.

Esse condicionamento histórico-cultural se mostra sobremaneira importante, porque o Mercosul significa, antes de tudo, livre circulação de bens, pessoas, capitais e serviços. Conseqüentemente, é justamente na ótica com que são vistas as transações comerciais e financeiras e os problemas alfandegários e aduaneiros que a maior diferença entre os sistemas jurídicos se faz notar.

Com efeito, no âmbito do Direito Privado e, particularmente, no Direito Comercial, termos quase homônimos cobrem significados distintos, se interpretados sob a luz do ordenamento privado alemão ou do ordenamento francês. Longe de serem problemas lingüísticos, tais questões dizem respeito à precisão conceitual e estão ligadas à compreensão de sistemas jurídicos gerados dentro de perspectivas específicas (FRADERA, 1997, p. 20). Uma colocação diferenciada de foco pode resultar em uma interpretação ambígua, conflitiva e controvertida no momento de regulamentar contratos e transações comerciais, os quais normalmente constituem a área predominante em um mercado comum

Por esses motivos, o Mercosul, realizado através de um discurso jurídico que tem nos termos técnicos contratuais e financeiros seu principal vetor, carece de ferramentas lingüísticas aptas a promover o intercâmbio e alicerçar os laços entre seus componentes. Pela natureza das disparidades dos sistemas lingüísticos e jurídicos, tais ferramentas devem abranger aspectos sócio-língüísticos, culturais e pragmáticos. Assim, não podem ser produzidas no formato usual dos glossários bilíngües, apresentando um inventário de termos compilados de maneira empírica e arranjados em listas de equivalentes refletidas como num espelho.

Se de alguma utilidade em áreas essencialmente técnicas, onde facilmente para cada termo se pode encontrar a correspondência de um conceito, nas áreas humanas, como o Direito, integralmente mediadas pela língua e estreitamente dependentes de um sistema cultural, o glossário bi ou multilíngüe, nesses moldes, se revela quase inútil, até mesmo enganador. Realmente, tais glossários e dicionários tornam-se perigosos, pois orientam mal o usuário, levando-o a conceitos completamente equivocados (DAVID, 1982, p. 430). E, ainda, no caso de oferecerem definições, podem agravar a situação, pois as definições de um vocabulário jurídico só têm valor para um país, uma época e um sistema jurídico dado (COUTURE, 1988, p. 20-21). Fortemente enraizados nos valores morais da sociedade da época, cada sistema nacional guarda características que fazem com que as normas e conceitos legais sejam encaradas sob perspectivas próprias (SANDRINI, 1996, p. 144).

Em suma, a multiplicidade de fatores sócio-culturais e de fatores lingüísticos tende a dificultar a compreensão mútua na área jurídica do Mercosul, onde aspectos diplomáticos e financeiros se conjugam e se contrapõem continuamente. Nesse contexto, um simples repertório de termos e equivalentes em português e em espanhol, por mais completo que seja não contempla de modo algum os problemas gerados pela incompreensão dos conceitos. Somente a explicitação do significado através da definição do termo dentro da respectiva cultura jurídica pode guiar o usuário na apreensão do sentido de uma lei ou de um regulamento. 


\section{Fundamentação teórica}

As características da conjuntura lingüístico-jurídica do bloco supranacional indicam que o desenvolvimento da terminografia para o Mercosul não pode se conformar com os pressupostos teóricos e as recomendações práticas usuais. De uma maneira geral até hoje, a quase unanimidade dos autores de instrumentos de referência de linguagens de especialidade concebe a unidade terminológica como a mera representação de um conceito por um signo lingüístico. Para eles, esse conceito faz parte de universo conceitual comum a todas as línguas, não dependendo dos condicionamentos do processo de comunicação. Dessa forma, a unidade terminológica, é uma entidade unívoca, definida por especialistas, inserida na estrutura cognitiva de um campo de saber ou atividade, passando a integrar a respectiva árvore de domínio. Organizadas em listas alfabéticas ou temáticas, essas unidades são os termos e seu conjunto compõe o inventário autorizado da terminologia da área.

Nessa ótica, terminologia compilada não admite o uso de sinônimos ou o aparecimento de variantes, morfológicas, semânticas ou sociológicas, que são consideradas imperfeições da linguagem e obstáculos para o fluxo ideal das informações. Dessa forma, os termos são concebidos como objetos estáticos num corpo monolítico de conhecimento, arquivados em dicionários e bancos de dados, devidamente identificados por etiquetas para serem usados por especialistas. A terminografia torna-se, sob esse prisma, atividade de cunho documentário que visa a arranjar catálogos de conceitos para serem acessados a partir de rótulos, preferentemente organizados em ordem temática e não alfabética, na forma de tesaurus.

Essa visão estática de uma terminografia mais cognitiva do que lingüística, mais preocupada com a recuperação da informação do que com o processo de comunicação, não se ajusta ao dinamismo do quadro lingüístico-jurídico da conjuntura sócio-político-cultural do Mercosul. Realmente, tal visão não dá conta da natureza e do propósito comunicacional da linguagem jurídica, privilegiando a feição ontológica e ignorando o aspecto pragmático.

Tal aspecto, no entanto, é privilegiado em outras perspectivas, tais como a sócio-terminologia (GAUDIN, 1993) e a Teoria Comunicativa da Terminologia (CABRÉ, 1998), que se afastam do universalismo lógico-mentalista tradicional. À luz dessas novas propostas, a terminografia jurídica do Mercosul poderá constituir bases teórico-metodológicas mais adequadas para a situação específica de seu desenvolvimento.

Do quadro referencial teórico das novas tendências, sublinho, como ponto chave o pressuposto de que a linguagem jurídica, como toda a linguagem de especialidade, é a língua comum usada em contexto especializado. Nesse sentido, a linguagem de especialidade participa de todas as propriedades da língua natural, constituindo-se em um sistema articulado de unidades sígnicas multifacetadas, os termos. Estes desempenham a função comunicativa por meio da tríplice conjunção do significante - denominação -, significado - conceito -, e referente -realidade - ativados em um contexto marcado pela especialização (CABRÉ, 1996).

Daí decorre que os termos são unidades lexicais que partilham de todas as características do sistema lingüístico da língua geral e, assim, compõem a competência do falante especialista. Dessa maneira, usados como qualquer unidade da língua natural, os termos desempenham tanto a função denotativa ou referencial, como a expressiva ou conotativa.

A função referencial não é exclusiva, pois não se limita ao processo de denominação ou individualização que seria o equivalente à atribuição de um nome próprio a um objeto, tampouco serve unicamente para posicionar o conceito numa nomenclatura, como é o caso de listas e taxionomias. Sua importância advém do papel mediador que o signo lingüístico desempenha na esfera cognitiva.

Com efeito, sem a mediação da língua, o conceito não se constitui, permanecendo uma noção nebulosa na mente de um indivíduo isolado. Através do signo lingüístico, se desencadeia a fase de construção do conceito e se efetiva o processo de comunicação. Dessa maneira, no universo do Direito, se dá o acesso, a identificação, a construção e a conseqüente aceitação de um conceito jurídico e, de outro lado, se instaura também sua transformação ou revogação, posto que os conceitos, tais como os termos, sofrer mutações no tempo e no espaço (GAUDIN 1996).

Assim, é o uso que confere valor terminológico à unidade lexical, ativando as virtualidades especificas da função que a unidade desempenha no ato comunicacional. De onde se deduz que o processo de comunicação é o catalisador das marcas de especialização que atribuem valor terminológico, conferindo estatuto de termo à palavra da língua comum.

As marcas de especialização do texto se compõem de uma reunião de fatores tanto de natureza cognitiva, como lingüística e pragmática. Os primeiros constituem a pertinência temática que, revelada através da língua pelos traços semânticos, vinculam o termo ao universo conceitual da área focalizada. Os fatores de natureza pragmática abrangem as características dos destinadores e destinatários da comunicação, seus propósitos e as circunstâncias da situação, configurando a pertinência pragmática (MACIEL, 1996).

A comunicação especializada se efetua, então, em um contexto em que ambos os aspectos de pertinência, temáticos e pragmáticos, têm vital importância. Os primeiros aparecem claramente em termos 
que são, por assim dizer transparentes, pois revelam a especificidade à primeira vista. Já os aspectos pragmáticos da pertinência se traduzem pela conjugação do estatuto dos actantes da comunicação, dos objetivos que eles se propõem, das circunstâncias em que se encontram, do tipo e do canal da mensagem comunicada.

Nesse sentido, os dois conceitos de pertinência podem ser ilustrados pelos termos salvaguarda e aditivo alimentar. No contexto do Mercosul, salvaguarda é uma figura de Direito Internacional. que significa basicamente uma cláusula inserida em contrato internacional de execução continuada. Mencionado em qualquer documento do Código do Mercosul, imediatamente produz o efeito de sentido desejado pelo destinador, a saber, tornar o destinatário consciente de que há determinadas restrições que protegem o contrato.

Já aditivo alimentar é termo originário da área temática de Engenharia de Alimentos, significando substância acrescentada ao alimento para conservar, intensificar ou modificar suas propriedades. Não obstante, faz parte da terminologia do Mercosul, porque, definido nos regulamentos de sanidade do Grupo Mercado Comum, visa à proteção da saúde na atividade de importação e exportação de produtos alimentares. Esse termo, para ser capaz de provocar o efeito de sentido especializado precisa estar inserido em documento oficial reconhecido pelos países membros e estar relacionado com a saúde pública. Dessa maneira, a conjuntura dos aspectos funcionais que compõem o quadro da legislação aduaneira de sanidade alimentar justifica sua inclusão no inventário da terminologia do Mercosul. Nesse caso, é a pertinência pragmática que se sobrepõe à pertinência temática, na atribuição do estatuto terminológico.

Tais exemplos mostram como a confluência dos traços das especificidades temática e pragmática confere ao termo o caráter especializado, isto é, sua pertinência à área. Assim, a especialização, concebida em função de um campo de conhecimento e/ou de uma área de atuação determinados, se manifesta na realização lingüística dentro de uma situação sócio-cultural dada. Donde se comprova que a terminologia do Mercosul se configura na realização da linguagem jurídica em um contexto discursivo específico.

Ademais, os dois termos acima mencionados ilustram, também, a incidência de palavras da língua comum na linguagem jurídica. De fato, a simples leitura dos documentos do Mercosul revela que os textos não se caracterizam por termos de uso exclusivo do Direito. Ao contrário, grande número de palavras da competência comum do falante são utilizadas para expressar conceitos do microuniverso jurídico dos relacionamentos do Cone Sul, passando a integrar sua terminologia. Tais unidades lexicais, como salvaguarda, não se singularizam quer pela morfologia, quer pela função sintática, e, não raras vezes, como no caso de aditivo alimentar, tampouco se distinguem por características semânticas.

Daí resulta a complexidade da tarefa de detectar os traços lingüísticos identificadores da especificidade da terminologia do Direito. Tal identificação, se não constitui problema para o jurista, mostra-se extremamente complexa para o terminógrafo que assume a tarefa de analisar a linguagem jurídica para realizar a coleta e seleção de candidatos a termo.

A prática tem revelado que procedimentos até agora usados, centrados seja na morfologia, seja na sintaxe, seja na semântica, não se têm mostrado satisfatórios para a identificação dos traços que ativam a especificidade de um termo (ESTOPÀ, 1999, p. 22). A insuficiência dos resultados dessas análises unilaterais justifica uma abordagem que englobe também o aspecto pragmático da comunicação em situação especializada (BEAUGRANDE, 1996, p. 16). Uma tal abordagem está de acordo com os pressupostos fundamentais acima expostos, conseqüentemente só pode ser empreendida a partir da análise de textos que veiculam a comunicação especializada. Dessa constatação, decorrem as bases metodológicas para o desenvolvimento da terminografia jurídica do Mercosul.

\section{Bases metodológicas}

A terminologia jurídica, objeto de estudo da terminografia do Mercosul, nasce nos textos dos tratados, acordos, protocolos, convenções, regulamentos, disposições e normas que regem o Mercado Comum do Cone Sul. Conforme já foi explanado, a existência dos termos, como vetores de ordenamento jurídico, depende estreitamente da língua e seu valor é ativado na realização discursiva dos documentos oficiais. Logo, o conjunto desses documentos constitui o corpus privilegiado para a pesquisa teórica e prática da terminologia jurídica do Mercosul.

Como se sabe, o uso de corpora textuais na pesquisa lingüística não é novidade. Os estruturalistas americanos já o faziam, reaplicando, em moldes científicos, uma prática utilizada na investigação das línguas mortas. Hoje, graças à proliferação dos recursos informatizados, esse uso alcançou um tal grau de sofisticação, demonstrado na aplicabilidade das ferramentas e na confiabilidade dos resultados, que originou uma ramificação dos estudos lingüísticos: a lingüística de corpus, (Habert et alii, 1997) da qual já deriva uma outra especialização, a terminologia computacional (BOURIGAULT et alii, 1999). 
O processamento automático ou semi-automático da terminologia é o objetivo último desse novel campo de estudos. Para realizar tal processamento, a terminologia computacional combina os atuais avanços científicos da terminologia como disciplina, com os progressos alcançados na teoria e na prática do processamento da linguagem natural e as mais recentes realizações da inteligência artificial. Assim, propõe técnicas e oferece ferramentas que ajudam eficientemente o terminólogo e/ou terminógrafo na pesquisa teórica e aplicada, bem como na atividade prática.

De fato, a contribuição da terminologia computacional torna viável a investigação da linguagem de especialidade em uma grande extensão de documentos e a coleta e seleção de termos em quantidades enormes de textos. Nessa direção, é oportunizada também a criação de bases de dados que podem ser continuamente gerenciadas e enriquecidas, além da editoração de dicionários e outro produtos impressos.

A terminografia computacional proporciona à terminografia e, no caso em foco, à terminografia jurídica para o Mercosul, a grande vantagem de permitir a busca das unidades lexicais com estatuto de termo, ou melhor dito, dos candidatos a termo no próprio contexto da comunicação, isto é, nos documentos autênticos. Essa circunstância, favorecida pelo fato de que esses documentos informatizados se encontram disponíveis, possibilita a operacionalização dos procedimentos de pesquisa textual e discursiva preliminares à coleta das unidades terminológicas. Além disso, facilita a atualização de uma terminologia que sofre acréscimos e mutações, posto que o Mercado Comum do Cone Sul é uma realidade dinâmica de relacionamentos internacionais selados por realizações lingüísticas escritas.

Os recursos que a terminologia computacional oferece para a investigação da linguagem jurídica estão sendo implementados em núcleos acadêmicos de pesquisa entre os quais podem ser citadas, entre outras, as universidades de Liverpool ${ }^{\mathrm{i}}$, na Inglaterra, Moncton ${ }^{\mathrm{ii}}$, no Canadá, Viena ${ }^{\mathrm{iii}}$, na Aústria, Nice Sophia-Antipolis $^{\mathrm{iv}}$, na França, Nova de Lisboa ${ }^{\mathrm{v}}$, Portugal e a Academia Européia de Bolzano ${ }^{\mathrm{vi}}$, e ainda a Universidade de Amsterdam na Holanda ${ }^{\text {vii }}$. Além desses centros, inúmeros grupos de pesquisa nesses países e também em outros, como na Dinamarca, na Holanda, na Bélgica e na Holanda, se dedicam à mesma área, incentivando cada vez mais os progressos dos estudos da terminologia e terminografia jurídicas.

Em suma, como decorrência dos pressupostos teóricos anteriormente comentados, utilizando os recursos de uma abordagem calcada nos ditames da terminologia computacional e ainda aproveitando da experiência e a pesquisa amplamente praticada na área, a metodologia básica da terminografia do Mercosul deverá ser desenvolvida a partir dos documentos oficiais. Tendo ainda em vista o já mencionado princípio de que a linguagem jurídica é a língua comum usada em situação especializada, é imprescindível adotar modelos comuns de descrição da língua, procurando sempre integrar os aspectos lingüísticos, conceituais e pragmáticos. Dessa forma, os procedimentos terminográficos obedecerão a uma metodologia coerente com os princípios defendidos, alcançando mais eficiência no tratamento e maior rigor científico na pesquisa da linguagem jurídica.

\section{Produção terminográfica}

Os resultados da pesquisa serão utilizados na produção de instrumentos de referência. Para que isto seja viável, deverão ser criadas bases de dados terminológicos, BDTs, que, processando as informações lingüísticas e conceituais obtidas na investigação dos documentos, poderão oferecer os meios para a elaboração de léxicos, vocabulários, glossários e dicionários, quer em formato papel, quer em formato eletrônico.

No entanto, é desejável que tais obras não sejam a mera repetição de modelos tradicionais impressos na forma convencional ou apresentados em suporte eletrônico. Tampouco é aconselhável que o desenho do BDT adote o padrão dos grandes BDTs, marcos históricos da terminografia européia e canadense.

Esses bancos cumpriram a missão de armazenar e tornar possível a recuperação de enormes quantidades de termos no passado. Hoje, no entanto, avanços dos estudos terminológicos exigem que sejam renovados. Novos caminhos se abrem, o termo já não é visto como item que estático que espera em um arquivo o momento de ser utilizado. Hoje, concebidos como unidades de conhecimento e comunicação, os termos são considerados unidades dinâmicas. De outro lado, os progressos da tecnologia oferecem recursos informatizados muito mais poderosos, possibilitando a estruturação de sistemas jamais imaginados há alguns anos atrás.

Na verdade, á não se concebe a criação de enormes BDTs, verdadeiros dinossauros, auto-suficientes e isolados. A tecnologia de redes, o mundo virtual da Internet e a familiaridade com que se trilham caminhos antes reservados a uns poucos especialistas sugerem a organização de bancos constituídos de muitas redes compostas pela interligação de bases de dados. Foi superada a fase pioneira dos gigantescos computadores que abrigavam grandes BDTs multitemáticos e multilíngües em estruturas sofisticadas, tais como o EURODICAUTOM, da UE, e o TERMIUM, da Secretaria de Estado do Canadá. A popularização das 
máquinas, hardware e a desmitificação das ferramentas, software, abriram caminho para a criação e o gerenciamento de BDTs cada vez mais especializados e de pequenas dimensões.

A idéia de uma rede de BDTs formada por diversos nódulos, constituídos por BDTs menores interligados não é nova, já foi anteriormente levantada, mas nunca posta em prática. No contexto do Mercosul, apoiada nos princípios teóricos expostos, parece ser a solução mais adequada ao desenvolvimento da terminografia.

Vários requisitos logísticos são indispensáveis, dos quais o mais premente é o consenso quanto à natureza e função das bases, estrutura dos nódulos e dos registros, além de um acordo sobre o formato de intercâmbio de dados. Muitos anteprojetos já foram elaborados, estudos de viabilidade realizados, desenhos de fichas discutidos, ferramentas adquiridas, não obstante, nunca se chegou a nenhuma realização concreta.

Neste sentido, o planejamento de um projeto piloto de um BTC para o Mercosul necessita partir da informação terminológica estruturada nos pequenos bancos que já operam na área. Reunindo os recursos existentes, se poderá prever a divisão da grande área em subáreas que, por sua vez, ainda poderão ser fragmentadas sucessivamente em outras menores. Para tanto, as áreas temáticas dos documentos que constituem a legislação do Mercosul serão usadas como as linhas gerais de um esquema. O nível de detalhamento poderá ser resolvido a posteriori, já que a classificação dos conceitos partirá do microuniverso analisado. (SAGER, 1990, p. 37).

A classificação propriamente dita poderá ser elaborada de acordo com a situação peculiar da subárea, sendo sua feição característica condicionada ao tempo e espaço sócio-político. Em outras palavras, nenhuma organização ou sistema classificatório importado poderá apresentar as condições adequadas, posto que essas serão decorrentes dos textos das do próprio Código do Mercosul. Assim sendo, os especialistas do próprio contexto do Mercosul deverão orientar e implementar os procedimentos de pesquisa.

Uma vez alimentados, os bancos de dados serão os geradores dos dicionários e outros instrumentos de referência. Entretanto, é preciso atentar que os dicionários jurídicos são exemplos típicos de dicionários culturalmente dependentes (BERGENHOTZ, TARP, 1995, p.63). Conseqüentemente, os dicionários do Mercosul serão elaborados nos moldes dos dicionários bilíngües orientados pelas culturas que estão compreendidas na região.

$\mathrm{Na}$ realidade, critérios especificamente culturais desempenham um papel significativo no processo do estabelecimento e da aplicação dos conceitos legais. E mais, o usuário não é obrigatoriamente falante nativo da língua do termo, isto é, aquele que procura o significado do termo espanhol não domina esse idioma, enquanto o falante de espanhol quer compreender o termo em português.

Por tudo isso, para ser bilíngüe e culturalmente orientado, o dicionário será também bidirecional, DBBCO. Assim, o termo será definido dentro do contexto do Mercosul, levando em consideração as peculiaridades dos sistemas jurídicos de cada país parte. Dessa forma, a definição do termo em português será redigida em espanhol, enquanto o termo em espanhol receberá uma definição escrita em português. Além disso, deverão ser contemplados também o guarani e as variantes lingüísticas das regiões envolvidas.

Nesse sentido, o dicionário bidirecional bilíngüe orienta o usuário tanto para a produção, quanto para a recepção de duas línguas simultaneamente (BERGENHOLTZ, TARP, idem, p. 52-54; O'NEIL; PALMER, 1992, p. 217; ROBERTS, 1992, p. 219). No caso do Mercosul, o dicionário bidirecional de termos jurídicos é um dicionário escrito para o falante de português compreender e falar a língua espanhola. Ao mesmo tempo, é um dicionário escrito para o falante de espanhol entender o português do Brasil e também se comunicar nesse mesmo português, sempre que se tratar do âmbito dos relacionamentos ditados pela lei.

A organização de um dicionário bidirecional prevê a composição de duas partes, como dois dicionários, $\mathrm{D}_{1}$ e $\mathrm{D}_{2}$ combinados em um único. Em cada um deles a língua de entrada é a língua estrangeira e a língua das definições e explicações, isto é, a metalinguagem é a língua nacional. No outro dicionário, acontece o inverso. Exemplificando, teremos uma parte em que os termos em espanhol serão explicados em português; outra parte em que os termos em português serão explicados em espanhol, enquanto as particularidades de cada sistema jurídico serão esclarecidas na língua do outro sistema.

A validade do dicionário bidirecional culturalmente orientado reside no seu potencial de harmonizar diferentes perspectivas culturais. Harmonizar não significa anular ou uniformizar, mas possibilitar a compreensão de outras maneiras de olhar o universo, implicando assim o respeito às características das nações parte. No caso do dicionário jurídico, o esclarecimento sobre os aspectos divergentes das concepções legais dos diferentes países contribuirá para o desenvolvimento de uma cultura de integração apontada por Morosini (1997) como o desafio sócio-linguiístico do Mercosul.

No entanto, o dicionário jurídico do Mercosul não será certamente apenas bilíngüe, espanhol/português-português/espanhol, tendo também equivalentes em inglês. O termo em inglês terá o caráter de uma aproximação funcional, jamais de uma equivalência e não será acompanhado de definição. A língua inglesa, colocada como língua veicular, servirá para abrir as janelas para o universo além da América Latina. Os países membros não podem conceber o relacionamento cultural e comercial apenas no seu circuito 
geográfico fechado, porquanto a expansão do Mercosul está em pleno curso. Países dos mais variados idiomas se interessam pelo o novo mercado, tornando a inclusão do inglês indispensável.

O papel dos produtos terminográficos jurídicos do Mercosul está em função direta da situação política, das necessidades e exigências do público alvo, formado por uma imensa gama de usuários. Além dos tradutores oficiais, destacam-se, nesse universo, os políticos e diplomatas, juntamente com documentalistas e bibliotecários, seguidos dos funcionários burocráticos das diferentes instâncias e conselhos da organização. Um segundo grupo abrange os juristas e os profissionais da mídia. Em menor proporção, encontram-se industriais, comerciantes, investidores das mais variadas áreas. Neste amplo leque de usuários, o denominador comum é a busca pela univocidade dos conceitos, visando à aplicação imediata da lei. Essa busca confere unidade ao objetivo do dicionário, orientando o processo de pesquisa dos termos, elaboração das definições e identificação dos vínculos semânticos e pragmáticos da rede de remissivas.

Em suma, a produção terminográfica do Mercosul tem um duplo propósito. Sua primeira finalidade é descritiva e consiste em esclarecer ao não especialista o conceito dos termos usados na língua de especialidade. A segunda é de natureza sociolingüística, a saber, contribuir para a fixação e normalização da terminologia de um campo especializado e assim, conseqüentemente, cooperar para a facilidade de comunicação entre os próprios especialistas.

\section{Conclusão}

Considerando o Mercosul sob o prisma de sistemas de diferentes orientações e de línguas em contato, proponho uma terminografia jurídica para o Mercosul que tenha condições de responder às exigências de uma realidade multifacetada. Para tanto, seus produtos, isto é, os instrumentos de referência serão elaborados, levando em conta a diversidade dos universos cognitivo, lingüístico e jurídico envolvidos.

As dificuldades para a elaboração desses instrumentos são enormes e se multiplicam a tal ponto que Tebbens (1982, p. 173-185), ao escrever sobre o desenvolvimento do projeto do dicionário jurídico holandês-francês, afirma que as metas propostas parecem utópicas e irrealizáveis. Não obstante, elas não são inatingíveis como já o demonstraram projetos bem sucedidos como o Terminologisches Wörterbuch zur Südtiroler Rechts- und Verwaltungssprache / Dizionario terminologico del linguaggio giuridico amnistrativo in Alto Adige (MAYER, 1998), gerado a partir de um banco de dados, alemão, italiano, em contínua atualização ${ }^{\text {viii }}$.

Em primeiro lugar, projeto dessa configuração é um trabalho essencialmente de uma equipe multinacional e multidisciplinar, na qual especialistas em assuntos para o Mercosul, juristas, documentalistas, lingüistas, tradutores terminólogos e terminógrafos harmonizem seus esforços. Em segundo lugar, dever ser um empreendimento que conte com apoio institucional, tanto acadêmico como governamental, que garanta os recursos humanos e materiais. Não é uma utopia, mas é algo que exige muito trabalho cooperativo e coordenação de esforços.

Concluindo, uma terminografia para o Mercosul terá características específicas decorrentes de sua própria natureza e das funções a desempenhar, não deverá adotar, portanto, os moldes tradicionais. O Mercosul é um contexto supranacional com personalidade própria, diferente de outras comunidades formadas pela reunião de nações. É preciso olhar para o que foi feito em comunidades semelhantes, sem nunca esquecer que o contexto do Mercosul é singular e requer um modelo específico.

\section{BIBLIOGRAFIA}

AUSTIN, J. L. How to do things with words. Cambridge, Mass.: Harvard University Press. 3 ed. 1978.

BAUER-BERNET, Hélène. Le multilinguisme du droit de la Communauté européenne. In: GEMAR, Jean Claude. Langage du droit et traduction: the language of the law and translation. Québec: Linguatech/Conseil de la langue française, 1982.

BEAUGRANDE, Robert de. LSP and terminology in a new science of text and discourse. In: GALINSKY, Christian; SCHMITZ, Klaus-Dirk. TKE' 96 Terminology and knowledge engineering. Frankfurt/M: INDEKS, 1996.

BERGENHOLTZ, Henning; TARP, Sven. Manual of specialised lexicography. Amsterdam: John Benjamins, 1995.

BESSÉ, Bruno de; NKWENTI-AZEH, Blaise; SAGER, J. C. Glossary of terms used in terminology. Terminology, 3 Amsterdam, John Benjamins, 1998. 
BOURIGAULT, Didier; JACQUEMIN, Christian; L'HOMME, Marie Claude. Presentattion of the Book on: Computational Terminology; Book Proposal, 1999. http://m17.limsi.fr/Individu/jacquemi/Computerm disponível em 10/08/99

CABRÉ, M. Teresa. Lexicología y variación: hacia un modelo integrado. In: Actas del V Simposio Iberoamericano de Terminología: Terminología, Ciencia y Tecnología, Ciudad del México, del 3 al 8 de noviembre de 1996.

CABRÉ, M.T. Elementos para una teoría de la terminología: hacia un paradigma alternativo. In: Lenguaraz, v.1, n.1, abril/1998.

COUTURE, Eduardo J. Vocabulario juridico; con especial referencia al Derecho Procesal Positivo vigente uruguayo. Buenos Aires: Delpalma, 1988.

DAVID, René. Les grands systèmes de droit contemporain. Paris: Dalloz, 1982.

DROMI, Roberto. Codigo del Mercosur. Buenos Aires: Ediciones Ciudad Argentina. 6 v, 1996.

ESTOPÀ, Rosa. Extracció de terminologia: elements per a la construcció d’un SEACUSE. Barcelona: Univeristat Pompeu Fabra, Institut Universitari de Lingüística Aplicada. [Tesi doctoral], 1999.

FRADERA, Vera Maria Jacob de. A circulação de modelos jurídicos europeus na América Latina: um entrave para a integração econômica do Cone Sul? In: Revista dos Tribunais. v. 736. fev.1997.

GAUDIN, François. Pour une socioterminologie. Des problèmees semantiques aux pratiques institutionnelles. Rouen: Publications de 1'Université de Rouen, 1993.

GAUDIN, François. Terminologie: 1'ombre du concept. In: Meta. v.41, n.4, 1996.

HABERT, Benoît; NAZARENKO, Adeline, SALEM, André. Les linguistiques de corpus. Paris: Armand Colin, 1997.

MACIEL, Anna Maria Becker. Pertinência pragmática e nomenclatura de um dicionário terminológico. In: Revista Internacional de Língua Portuguesa. n.15. Lisboa: Associação das Universidades de Língua Portuguesa, 1997.

MAYER, Felix. Terminologisches Wörterbuch zur Südtiroler Rechts- und Verwaltungssprache / Dizionario terminologico del linguaggio giuridico amnistrativo in Alto Adige. Bolzano: Accademia Europea, 1998.

MOROSINI, Marília Costa. MERCOSUL: desafios sócio-lingüísticos da integração. Primer Seminário de Integración Sócio-linguístico. Consejo General de Cultura y Educación de la Província de Buenos Aires, Mar del Plata, 25 de abril de 1997.

O'NEIL, Mary; PALMER, Catherine. Editing a bilingual dictionary entry within the framework of a bidirectional dictionary. In: EURALEX'90. Actas del III Congreso Internacional. Barcelona: Bibliograf, 1992.

PALMISCIANO, Giuseppe; CHRISTOFFERSEN., Jens. Aspects linguistiques de la Communication juridique en Europe: pratique et problèmes de "jusristes-reviseurs" de la Comission des Communautés Européenes. Il Diritto Privato Europeo: Problemi e Prospettive. Atti del Convegno Internazionale. Macerata, 8-10 Giugno, 1989. Milano: Giuffrè Editore, 1993.

ROBERTS, Roda P. Organization of information in a bilingual dictionary entry. In: EURALEX'90. Actas del III Congreso Internacional. Barcelona: Bibliograf., 1993.

SAGER, J.C. A Practical course in terminology processing. Amsterdam: John Benjamins, 1990.

SANDRINI, Peter. Terminologiearbeit im Recht Deskriptiver begriffsorientierter Ansatz, vom Standpunkt des Übersetzers. Vienna: TermNet, 1995.

SANDRINI, Peter. Comparative analysis of legal terms: equivalence revisited. In: GALINSKI, Christian; SCHMITZ, Klaus-Dirk (eds.). TKE'96: Terminology and knowledge engineering. Frankfurt: Indeks, 1996.

SARCEVIC, Susan Bilingual and multilingual legal dictionaries: new standards for the future. In: Meta, v.36, n.4, 1991.

TEBBENS, Harry D. Le dictionnaire juridique néerlandais-français: un exercice de droit comparé. In: GEMAR, Jean Claude. Langage du droit et traduction: the language of the law and translation. Québec: Linguatech/Conseil de la langue française, 1982.

\footnotetext{
${ }^{\mathrm{i}}$ http://www.csc.liv.ac.uk/ pepijn

ii http://www.umoncton.ca/cttj/cttj_2/juriterm2.html

iii http://www.ifs.univie.ac.at/law/humanities/konterm/konterm.html

iv http://floripa.unice.fr

${ }^{v}$ http://coluna.di.fct.unl.pt/ pgrd

vi http://www2.eurac.edu

vii http://www.Lri.jur.uva.nl
} 